\title{
Clinical Study \\ Effects of Aquajogging in Obese Adults: A Pilot Study
}

\author{
Eveline J. M. Wouters, ${ }^{1,2}$ Annemieke M. A. Van Nunen, ${ }^{3}$ Rinie Geenen, ${ }^{4}$ \\ Ronette L. Kolotkin, ${ }^{5,6}$ and Ad J. J. M. Vingerhoets ${ }^{2}$ \\ ${ }^{1}$ Department of physiotherapy, Fontys University of Applied Sciences, P.O. Box 347, 5600 AH Eindhoven, The Netherlands \\ ${ }^{2}$ Clinical Psychology Section, Tilburg University, P.O. box 90153, 5000 LE Tilburg, The Netherlands \\ ${ }^{3}$ PsyQ, Anderlechstraat 17, 5628 WB Eindhoven, The Netherlands \\ ${ }^{4}$ Department of Clinical and Health Psychology, Utrecht University, P.O. Box 80140, 3508 TC Utrecht, The Netherlands \\ ${ }^{5}$ Obesity and Quality of Life Consulting, 762 Ninth Street, Durham, NC 27705, USA \\ ${ }^{6}$ Department of Community and Family Medicine, Duke University School of Medicine, Durham, NC 27710, USA
}

Correspondence should be addressed to Eveline J. M. Wouters, e.wouters@fontys.nl

Received 27 May 2009; Revised 28 June 2009; Accepted 20 July 2009

Academic Editor: Jonatan R. Ruiz

Copyright () 2010 Eveline J. M. Wouters et al. This is an open access article distributed under the Creative Commons Attribution License, which permits unrestricted use, distribution, and reproduction in any medium, provided the original work is properly cited.

\begin{abstract}
Aim and Method. To examine in obese people the potential effectiveness of a six-week, two times weekly aquajogging program on body composition, fitness, health-related quality of life, and exercise beliefs. Fifteen otherwise healthy obese persons participated in a pilot study. Results. Total fat mass and waist circumference decreased $1.4 \mathrm{~kg}(P=.03)$ and $3.1 \mathrm{~cm}(P=.005)$, respectively. The distance in the Six-Minute Walk Test increased 41 meters $(P=.001)$. Three scales of the Impact of Weight on Quality of Life-Lite questionnaire improved: physical function $(P=.008)$, self-esteem $(P=.004)$, and public distress $(P=.04)$. Increased perceived exercise benefits $(P=.02)$ and decreased embarrassment $(P=.03)$ were observed. Conclusions. Aquajogging was associated with reduced body fat and waist circumference and improved aerobic fitness and quality of life. These findings suggest the usefulness of conducting a randomized controlled trial with long-term outcome assessments.
\end{abstract}

\section{Introduction}

Of the more than 1 billion overweight adults, at least 300 million are obese (Body Mass Index $[\mathrm{BMI}]>30 \mathrm{~kg} / \mathrm{m}^{2}$ ) $[1$, 2 ]. Obesity increases the risk of chronic diseases, particularly cardiovascular disease [3-5], type II diabetes mellitus [6, $7]$, and osteoarthritis $[8,9]$ in adults. Quality of life is severely reduced in obese persons $[10,11]$, and it is related to the degree of overweight [12]. Both obesity and living a sedentary life have been associated independently with decreased quality of life [13] and stress regulation [14].

Physical exercise, combined with dietary adjustments, massages, and baths, has been recommended for obesity since Hippocrates (fourth century BC) [15]. Aerobic exercise produces less weight loss compared to caloric restriction programs [16]. Some recent studies, however, give evidence for weight loss, especially abdominal weight loss, as a result of exercise without caloric restriction [17-19]. Given the benefits for both physical and mental health [20], exercise has been widely recommended to reduce the health risks associated with overweight and obesity, even if the weight loss is minimal $[19,21,22]$. However, there is a substantial elevated risk of injuries in obese persons, especially sprains and strains [23].

Physical exercise in water is a possibility to try to increase physical and mental health of obese persons without the risk of injuries. Aerobic activities in water have been found to be effective to improve aerobic fitness [24], and the effect on body composition has been demonstrated to be similar to weight-bearing aerobic exercise on land [25]. Aquajogging is a specific form of exercise which consists of simulated running in deep water. In sports, aquajogging is used as low-impact training, for example, in the rehabilitation phase after an injury. Aquajogging has been applied as a joint sparing intervention in rheumatologic diseases such as osteoarthritis, in the pre- and postoperative management of musculoskeletal diseases, and as an endurance and power training in cardiorespiratory disease [26-28]. According to 
a search in the international reference system Web of Science, aquajogging as an intervention to improve physical and mental health in obese people has not been evaluated up till now.

The aim of this pilot study was to examine the safety and potential effectiveness of a six-week aquajogging exercise program on body composition, aerobic fitness, and healthrelated quality of life and exercise beliefs in obese people.

\section{Materials and Methods}

2.1. Participants. Participants were recruited with advertisements in a local paper, a poster in the waiting-room of local general practitioners, and an appeal on the website of the Dutch Obesity Association. Inclusion criteria were a BMI of at least $30 \mathrm{~kg} / \mathrm{m}^{2}$, age between 18 and 65 years, and the intention to miss no more than two out of twelve training sessions. Exclusion criteria were an identified somatic disease and use of medications. The first 15 obese people who applied for the intervention and fulfilled the inclusion and exclusion criteria were invited to participate. The study was approved by the institutional review board of Reinier van Arkel group (mental health care department, 's-Hertogenbosch) and all participants provided written informed consent.

2.2. Aquajogging Program. Participants enrolled in a standard aquajogging program consisting of warming up, running in deep water alternated with extra arm and leg exercises, and cooling down, on stimulating music adapted to the phase of the program [29]. Twelve sessions were given, two times per week during six weeks. Four physiotherapy graduate students alternatively carried out the program. Each session lasted for one hour. Every participant could train at his or her own level, although they were stimulated by their trainer to gradually increase their effort throughout the session.

2.3. Anthropometry and Body Composition. Height was measured using a tape measure fixed to the wall with participants on bare feet. Body weight, fat mass, and fat percentages were measured with the Tanita tbf $-300 \mathrm{~m}$ [30, 31]. The Tanita, a bioimpedance analysis method to measure body composition, has proven to be valid in obese people [32], especially when monitoring modest changes in fat [33]. Waist circumference was measured with a special waist circumference tape measure using the iliac crest as a landmark. Measures were taken in duplicate and averaged.

2.4. Aerobic Fitness. The Six-Minute Walk Test (6MWT) was performed outdoors in comfortable weather circumstances according to the procedure as described by the American Thoracic Society [34]. Participants were instructed to walk as much distance as possible without running in six minutes; encouragement was given as recommended [34]. The 6MWT is a valid and reproducible tool to measure aerobic fitness in a group of obese people [35]. Heart rate values during rest and immediately after the 6MWT were measured three times and averaged, using the MD300-D finger pulse oximeter
(Medisane). After the 6MWT the modified Borg scale was applied to assess exertion. This measure consists of a visual analog scale measurement ranging from 0 (no exertion) to 10 (extreme exertion) [36-38].

2.5. Health-Related Quality of Life. Health-related quality of life was measured using the Dutch version of the IWQOLLite (short form of Impact of Weight on Quality of Life) questionnaire. The IWQOL-Lite is a 31 item, obesity-specific health-related quality of life questionnaire. It consists of five scales: physical function, self-esteem, sexual life, public distress, and work [39]. The IWQOL-Lite has been shown to have good internal consistency (Cronbach's $\alpha$ range from .90 to .96) [40], good test-retest reliability (correlations range from .83 to .94) [39], responsiveness to weight loss and weight gain $[41,42]$, sensitivity to treatment seeking status [12] and degree of obesity [43], and a scale structure supported by confirmatory factor analysis [40].

2.6. Exercise Beliefs. Perceived barriers and benefits of physical exercise were measured with the Physical Exercise Belief Questionnaire (PEBQ) [44]. The PEBQ is partly derived from the Dutch version of the Tampa scale of Kinesiophobia [45] and consists of four scales. Two scales (fear of injury and embarrassment) measure exercise barriers (high scores indicate high perceived barriers), and two scales (confidence and exercise benefits) measure health benefits of exercise and exercise self confidence (high scores indicate high perceived benefits). The psychometric characteristics of the PEBQ have proved to be satisfactory in a sample of 278 obese and severely obese patients [44].

Self-efficacy was assessed with The Dutch version of the 18-item Exercise Self-Efficacy Scale [46].

2.7. Physical Activity. Recent and current exercise behavior was measured by asking "do you engage in sportive activities?" (response alternatives: yes or no), an open ended question about the nature of these activities, and the time spent on these activities weekly during the past year, using a 5-point scale response format ranging from "less than one hour per week" to "more than four hours per week." Walking and cycling activities during daily life, like shopping, going to work, or going to school, were rated on a five point scale, ranging from less than five minutes per day to more than 45 minutes per day.

2.8. Qualitative Evaluation. A brief individual open interview with all participants after three and after six weeks of training evaluated the aquajogging program and its effects on daily activities as well as experienced negative effects during and after training, such as injuries or muscular pain. All interviews were performed at the same time for all participants, after three and six weeks of training.

2.9. Statistical Analysis. The mean changes between the baseline assessment scores and the scores after the aquajogging program were compared for BMI, fat percentage, fat mass and waist circumference, the distance covered in 
TABle 1: Anthropometric and demographic characteristics at baseline.

\begin{tabular}{lc}
\hline Age, mean (range) years & $44(28-60)$ \\
Number of participants, male/female & $2 / 13$ \\
Body weight, mean (SD) kg & $105.6(13.2)$ \\
Body Mass Index, mean (SD) kg/m² & $37.9(5.0)$ \\
Educational level, $n(\%)$ & \\
$\quad<9$ years of education & $3(20)$ \\
9-12 years of education, no high school degree & $2(13)$ \\
High school graduates & $5(33)$ \\
Bachelor or Master degree & $5(33)$ \\
\hline
\end{tabular}

the $6 \mathrm{MWT}$, and the heart rate during rest and immediately after the 6MWT, the Borg exertion rating, the scale scores on the IWQOL-Lite, the PEBQ, and the Exercise Self-Efficacy Scale. Considering the small sample size, the nonparametric Wilcoxon-signed ranks test was used to examine the significance of the differences between baseline and at six weeks. All analyses were conducted using the program Statistical Package for the Social Sciences (SPSS Version 14.0; SPSS Inc., Chicago, IL, USA). Results are presented as mean (SD).

\section{Results}

3.1. Descriptives. Fifteen otherwise healthy obese persons entered the program. Anthropometric and demographic characteristics at baseline are presented in Table 1. One (male) participant dropped out of the study a week before the end of the program because of a respiratory infection. Thirteen of the participants were women with a mean age of 44 years and a mean BMI of $38 \mathrm{~kg} / \mathrm{m}^{2}$. One woman used antidepressive medication (Duloxetine), a serotonin and noradrenalin reuptake inhibitor not influencing body weight [47], $60 \mathrm{mg}$ daily. The mean participants' self-reported daily physical activity, including sportive activities, was less than 30 minutes. No diets with the intention of extra weight loss were used during the program.

3.2. Changes in Body Composition. Weight, BMI, and fat percentage were lower after six weeks compared to baseline, but the differences were not statistically significant (Table 2). Fat mass decreased in 11 and increased in 3 participants. The change of fat mass from 48.5 (10.5) to 47.1 (10.8) $\mathrm{kg}$ was significant $(P<.05)$. Waist circumference decreased in 12 and increased in two participants (a statistically significant change, $P<.01)$.

3.3. Changes in Aerobic Fitness. The distance walked in the 6MWT was significantly longer after six weeks of aquajogging; it changed from 574 (42) to 615 (37) meters $(P<.01)$ (Table 2$)$; all participants showed an increase in walking distance. Both heart rate and perceived exertion after the 6 MWT did not alter after 6 weeks of aquajogging.

3.4. Changes in Health-Related Quality of Life. The scores on all scales of the IWQOL-Lite in the study group reflected a poor quality of life at baseline (Table 3): the scores were on average $10 \%$ to $20 \%$ lower than the scores in the general population [10]. The scores on three scales of the IWQOLLite significantly improved after six weeks of aquajogging: physical function increased from 62.8 (24.2) to 70.2 (21.7), $P<.01$, self-esteem increased from 60.2 (26.5) to 70.2 (21.7), $P<.01$, and public distress increased from 78.2 (17.8) to 83.0 (14.3), $P<.05$.

3.5. Changes in Exercise Beliefs. The PEBQ showed a significant $(P<.05)$ increase in perceived exercise benefits after six weeks of aquajogging (Table 3). Eight out of 14 participants indicated increased perceived exercise benefits, one participant perceived decreased exercise benefits, and five showed no changes. Ten of 14 participants indicated decreased and three increased embarrassment, the mean change being statistically significant $(P<.05)$. Fear of injury, confidence, and exercise self-efficacy did not show any significant change after 6 weeks of aquajogging (Table 3 ).

3.6. Qualitative Evaluation. Thirteen participants were very positive about aquajogging as a way of physical exercise. All participants perceived improved aerobic fitness in daily life and reported improved self confidence. Most participants reported decreased clothing size. Participants experienced decreased appetite, and three spontaneously made an appointment with a dietician to start dietary treatment after the end of the aquajogging program. Injuries or uncomfortable muscular pain were not experienced by any participant during or after the training. All participants valued the fact that they exercised in a group with the same obese condition.

\section{Discussion}

After a 6-week aquajogging group program without dietary restriction in obese people, improvements in body composition, aerobic fitness, and quality of life were observed.

With respect to weight loss, our study is in agreement with previous findings that weight loss is limited after physical activity as monotherapy [16]. Some studies suggest that physical exercise may result in — at best—-modest weight loss independent of the effect of caloric reduction through diet [17-19]. These studies employed strenuous physical exercise regimes equal to a daily energy expenditure of $500 \mathrm{kcal}$ (women) or $700 \mathrm{kcal}$ (men). Although we did not measure this variable, the reduction in energy expenditure is supposed to be low in our intervention, because the program lasted for one hour regardless of caloric loss and was performed only twice a week. If the training program had covered a longer period of time, with higher frequency and intensity, better results on weight would have been expected. On the other hand, although the relatively low intensity of aquajogging may make it less effective to lose weight, it is considered a suitable intervention for obese people, because they perceive it as a positive exercise experience, which has been reported as being important in previous studies focused on physical exercise with obese patients [48]. 
TABLE 2: Effects of aquajogging on body composition and aerobic fitness of 14 participants, means (SD). BMI: Body Mass Index; HR: heart rate; 6MWT: 6 minute walk test.

\begin{tabular}{|c|c|c|c|}
\hline & Baseline & Six weeks & $P$ values $^{1}$ \\
\hline \multicolumn{4}{|l|}{ Body composition } \\
\hline Weight (kg) & $106.1(13.7)$ & $104.7(14.1)$ & .06 \\
\hline $\operatorname{BMI}\left(\mathrm{kg} / \mathrm{m}^{2}\right)$ & $38.2(5.0)$ & $37.7(5.1)$ & .06 \\
\hline Fat percentage $(\%)$ & $45.5(5.9)$ & $44.7(6.1)$ & .06 \\
\hline Fat mass $(\mathrm{kg})$ & $48.5(10.5)$ & $47.1(10.8)$ & .03 \\
\hline Waist circumference $(\mathrm{cm})$ & $113.5(10.4)$ & $110.4(10.4)$ & .005 \\
\hline \multicolumn{4}{|l|}{ Aerobic fitness } \\
\hline HR rest (bpm) & $85(14)$ & $82(13)$ & .60 \\
\hline HR after 6MWT (bpm) & $131(19)$ & $135(21)$ & .18 \\
\hline Distance 6MWT (m) & $574(42)$ & $615(37)$ & .001 \\
\hline Borg exertion score & $5.3(1.6)$ & $6.2(1.8)$ & .11 \\
\hline
\end{tabular}

TABLE 3: Health-related quality of life and exercise beliefs of 14 participants: means (SD).

\begin{tabular}{lccc}
\hline & Baseline & Six weeks & $P$ values $^{1}$ \\
\hline IWQOL-Lite $^{2}$ & & & \\
$\quad$ Physical function & $62.8(24.2)$ & $69.8(18.5)$ & .008 \\
Self-esteem & $60.2(26.5)$ & $70.2(21.7)$ & .004 \\
Sexual life & $84.8(20.8)$ & $88.8(13.5)$ & .26 \\
Public distress & $78.2(17.8)$ & $83.0(14.3)$ & .04 \\
Work & $90.2(10.0)$ & $91.3(9.0)$ & .60 \\
\hline PEBQ & & & .75 \\
Fear of injury & $9.9(4.0)$ & $9.6(3.2)$ & .03 \\
Embarrassment & $12.6(4.3)$ & $10.4(4.5)$ & .48 \\
Confidence & $8.7(2.6)$ & $9.1(3.0)$ & .02 \\
Exercise benefits & $17.4(1.8)$ & $18.3(2.0)$ & .28 \\
\hline Exercise Self-Efficacy & $67.3(16.6)$ & $70.4(16.8)$ & \\
\hline
\end{tabular}

${ }^{1}$ Wilcoxon signed ranks test.

${ }^{2}$ IWQOL-Lite: Impact of weight on quality of life-short form.

${ }^{3}$ PEBQ: Physical Exercise Belief Questionnaire.

Physical activity has been recommended for obese persons because it increases cardiorespiratory fitness independent of caloric loss $[49,50]$. Obese persons are more likely to have hypertension, dyslipidemia, and the metabolic syndrome $[51,52]$. Exercise training has been found to decrease heart rate at rest [53], but a substantial effect of aquajogging on resting heart rate was not found in our study, perhaps because the duration, frequency, or intensity of the training was too low [54]. Obesity-related comorbid conditions (especially insulin resistance) have been found to be reduced by increased daily physical activity without caloric restriction [18]. Our study observed a significant reduction of fat mass and waist circumference, a visceral fat measure that is a risk indicator for comorbidity $[55,56]$. The results of our pilot intervention in obese people suggest that promising health effects can be expected from aquajogging, even when weight loss is minimal.

We used the Six-Minute Walk test as a measure of functional capacity [34]. The mean baseline walking distance observed in our obese participants was slightly lower than that reported in healthy adults [57]. The mean increase in walking distance of 41 meters is in between the effect of corticosteroid inhalation, and exercise and diaphragmatic strength training, in COPD patients [34]. This possibly clinically relevant change in distance should be interpreted with some caution. Perhaps the results are partly due to the learning effect of doing the test for the second time [35]. Our study did not find positive effects of aquajogging on exertion scores after the walking test. However, because baseline exertion and postintervention exertion scores related to a different physical performance after the walking test on the two occasions, our study does not allow a final evaluation of effects of aquajogging on physical exertion. Perhaps increased confidence made the participants to exceed their limits in the walking test after the intervention.

After the aquajogging program, the health-related quality of life scores of our participants showed an improvement in public distress and in the scales that normally deviate most from normal weight people: physical function and self-esteem $[10,12]$. In addition, exercise embarrassment 
decreased, and the perception of exercise benefits increased after the aquajogging program, as indicated by the PEBQ findings and the open interviews. Our pilot study shows that quality of life improves and suggests that aquajogging might bring about these effects.

Aquatic exercise has been proved beneficial in other patients with conditions who are at risk when performing strenuous exercise like osteoarthritis [27, 58, 59], fibromyalgia [60], and sports injuries [28]. The severely obese people also belong to this group for whom aquatic exercise may be the physical exercise intervention of choice, because they are unable to perform large amounts of exercise over the short term [61], and there is a substantial risk of injury [23]. In our study, no participants experienced any injury suggesting that aquajogging might be a safe way of exercising in obesity.

There are limitations to the present study, including the small sample size, the predominance of women, the lack of a randomized, untreated control group, the relatively short duration of the intervention, and the absence of a follow up evaluation to examine persistence of effects. Future evaluations of aquajogging programs should include muscular fitness, because higher resistance against the limbs' movement created by the water could improve both cardiorespiratory and muscular fitness. This was not tested in our study. Because it was considered of utmost importance that participants learned to like physical exercise, we did not stimulate high-intensity exercise and did not repeatedly assess variables such as heart rate, Borg's perceived exertion scale, or training diaries. Our study did also not take into account possible concomitant dietary changes. As in many other studies, our study population consisted of participants who volunteered for the program. This restricts the generalizability of the results to obese people who may be considered motivated to participate in this kind of intervention.

\section{Conclusions}

Physical exercise in water is a possibility to try to increase physical and mental health of obese persons without the risk of injuries. In a six-week open-trial in obese persons, aquajogging without caloric restrictions was associated with reductions in body fat and waist circumference and with improvement of aerobic fitness and quality of life. These findings suggest the usefulness of conducting a randomized controlled trial with long-term outcome assessments. The indication that aquajogging results in physical and mental health benefits for obese people suggests that it might be a valuable therapy in itself or as an adjunct to a dietary intervention.

\section{Acknowledgments}

The authors wish to thank Thijs van Bree, Stefan Janssen, Servé van Veggel, and Rob Westerlaken for their excellent supervising, testing, and training the participants of this study, and the staff of Thermae Son, who kindly provided all swimming facilities.

\section{References}

[1] WHO, "Global strategy on diet, physical activity and health," 2009.

[2] B. M. Popkin, "Global nutrition dynamics: the world is shifting rapidly toward a diet linked with noncommunicable diseases," American Journal of Clinical Nutrition, vol. 84, no. 2, pp. 289-298, 2006.

[3] F. Abbasi, B. W. Brown Jr., C. Lamendola, T. McLaughlin, and G. M. Reaven, "Relationship between obesity, insulin resistance, and coronary heart disease risk," Journal of the American College of Cardiology, vol. 40, no. 5, pp. 937-943, 2002.

[4] C. Curioni, C. André, and R. Veras, "Weight reduction for primary prevention of stroke in adults with overweight or obesity," Cochrane Database of Systematic Reviews, no. 4, Article ID CD006062, 2006.

[5] J. R. Ghosh and A. R. Bandyopadhyay, "Comparative evaluation of obesity measures: relationship with blood pressures and hypertension," Singapore Medical Journal, vol. 48, no. 3, pp. 232-235, 2007.

[6] C. Daousi, I. F. Casson, G. V. Gill, I. A. MacFarlane, J. P. H. Wilding, and J. H. Pinkney, "Prevalence of obesity in type 2 diabetes in secondary care: association with cardiovascular risk factors," Postgraduate Medical Journal, vol. 82, no. 966, pp. 280-284, 2006.

[7] M. Serrano Rios, "Relationship between obesity and the increased risk of major complications in non-insulindependent diabetes mellitus," European Journal of Clinical Investigation, vol. 28, supplement 2, pp. 14-18, 1998.

[8] C. B. Eaton, "Obesity as a risk factor for osteoarthritis: mechanical versus metabolic," Medicine and Health, vol. 87, no. 7, pp. 201-204, 2004.

[9] A. Powell, A. J. Teichtahl, A. E. Wluka, and F. M. Cicuttini, "Obesity: a preventable risk factor for large joint osteoarthritis which may act through biomechanical factors," British Journal of Sports Medicine, vol. 39, no. 1, pp. 4-5, 2005.

[10] A. M. A. Van Nunen, E. J. M. Wouters, A. J. J. M. Vingerhoets, J. J. Hox, and R. Geenen, "The health-related quality of life of obese persons seeking or not seeking surgical or non-surgical treatment: a meta-analysis," Obesity Surgery, vol. 17, no. 10, pp. 1357-1366, 2007.

[11] R. L. Kolotkin, K. Meter, and G. R. Williams, "Quality of life and obesity," Obesity Reviews, vol. 2, no. 4, pp. 219-229, 2001.

[12] R. L. Kolotkin, R. D. Crosby, and G. R. Williams, "Healthrelated quality of life varies among obese subgroups," Obesity Research, vol. 10, no. 8, pp. 748-756, 2002.

[13] G. T. C. Ko, "Both obesity and lack of physical activity are associated with a less favorable health-related quality of life in Hong Kong Chinese," American Journal of Health Promotion, vol. 21, no. 1, pp. 49-52, 2006.

[14] A. Tsatsoulis and S. Fountoulakis, "The protective role of exercise on stress system dysregulation and comorbidities," Annals of the New York Academy of Sciences, vol. 1083, pp. 196213, 2006.

[15] G. A. Bray, "Obesity: historical development of scientific and cultural ideas," International Journal of Obesity, vol. 14, no. 11, pp. 909-926, 1990.

[16] W. C. Miller, D. M. Koceja, and E. J. Hamilton, "A metaanalysis of the past 25 years of weight loss research using diet, exercise or diet plus exercise intervention," International Journal of Obesity, vol. 21, no. 10, pp. 941-947, 1997.

[17] R. Ross, D. Dagnone, P. J. H. Jones, et al., "Reduction in obesity and related comorbid conditions after diet-induced weight 
loss or exercise-induced weight loss in men: a randomized, controlled trial," Annals of Internal Medicine, vol. 133, no. 2, pp. 92-103, 2000.

[18] R. Ross, J. A. Freeman, and I. Janssen, "Exercise alone is an effective strategy for reducing obesity and related comorbidities," Exercise and Sport Sciences Reviews, vol. 28, no. 4, pp. 165-170, 2000.

[19] R. Ross, I. Janssen, J. Dawson, et al., "Exercise-induced reduction in obesity and insulin resistance in women: a randomized controlled trial," Obesity Research, vol. 12, no. 5, pp. 789-798, 2004.

[20] F. J. Penedo and J. R. Dahn, "Exercise and well-being: a review of mental and physical health benefits associated with physical activity," Current Opinion in Psychiatry, vol. 18, no. 2, pp. 189 193, 2005.

[21] D. L. Heim, C. A. Holcomb, and T. M. Loughin, "Exercise mitigates the association of abdominal obesity with high-density lipoprotein cholesterol in premenopausal women: results from the third National Health and Nutrition Examination Survey," Journal of the American Dietetic Association, vol. 100, no. 11, pp. 1347-1353, 2000.

[22] K. Shaw, H. Gennat, P. O'Rourke, and C. Del Mar, "Exercise for overweight or obesity," Cochrane Database of Systematic Reviews, no. 4, Article ID CD003817, 2006.

[23] E. A. Finkelstein, H. Chen, M. Prabhu, J. G. Trogdon, and P. S. Corso, "The relationship between obesity and injuries among U.S. adults," American Journal of Health Promotion, vol. 21, no. 5, pp. 460-468, 2007.

[24] T. P. Reilly, C. N. Dowzer, and N. T. Cable, "The physiology of deep-water running," Journal of Sports Sciences, vol. 21, no. 12, pp. 959-972, 2003.

[25] E. Gappmaier, W. Lake, A. G. Nelson, and A. G. Fisher, "Aerobic exercise in water versus walking on land: effects on indices of fat reduction and weight loss of obese women," Journal of Sports Medicine and Physical Fitness, vol. 46, no. 4, pp. 564-569, 2006.

[26] A. Cider, M. Schaufelberger, K. S. Sunnerhagen, and B. Andersson, "Hydrotherapy-a new approach to improve function in the older patient with chronic heart failure," European Journal of Heart Failure, vol. 5, no. 4, pp. 527-535, 2003.

[27] A. Foley, J. Halbert, T. Hewitt, and M. Crotty, "Does hydrotherapy improve strength and physical function in patients with osteoarthritis - a randomised controlled trial comparing a gym based and a hydrotherapy based strengthening programme," Annals of the Rheumatic Diseases, vol. 62, no. 12, pp. 1162-1167, 2003.

[28] R. Zenhausern and W. O. Frey, "Aquajogging in the rehabilitation process," Orthopade, vol. 26, pp. 926-929, 1997.

[29] A. Van der Sluis, "Aquajogging, fitness programma met de wet belt [aquajogging, fitness program with a flotation belt]," Doorn, N.R.Z., 1993.

[30] S. A. Jebb, T. J. Cole, D. Doman, P. R. Murgatroyd, and A. M. Prentice, "Evaluation of the novel Tanita body-fat analyser to measure body composition by comparison with a fourcompartment model," British Journal of Nutrition, vol. 83, no. 2, pp. 115-122, 2000.

[31] J. D. Ritchie, C. K. Miller, and H. Smiciklas-Wright, “Tanita foot-to-foot bioelectrical impedance analysis system validated in older adults," Journal of the American Dietetic Association, vol. 105, no. 10, pp. 1617-1619, 2005.

[32] G. W. Strain, J. Wang, M. Gagner, A. Pomp, W. B. Inabnet, and S. B. Heymsfield, "Bioimpedance for severe obesity: comparing research methods for total body water and resting energy expenditure," Obesity, vol. 16, no. 8, pp. 1953-1956, 2008.

[33] M. Neovius, J. Uddén, and E. Hemmingsson, "Assessment of change in body fat percentage with DXA and eight-electrode BIA in centrally obese women," Medicine and Science in Sports and Exercise, vol. 39, no. 12, pp. 2199-2203, 2007.

[34] R. O. Crapo, R. Casaburi, A. L. Coates, et al., "ATS statement: guidelines for the six-minute walk test," American Journal of Respiratory and Critical Care Medicine, vol. 166, no. 1, pp. 111$117,2002$.

[35] U. E. Larsson and S. Reynisdottir, "The six-minute walk test in outpatients with obesity: reproducibility and known group validity," Physiotherapy Research International, vol. 13, no. 2, pp. 84-93, 2008.

[36] R. C. Wilson and P. W. Jones, "Long-term reproducibility of Borg scale estimates of breathlessness during exercise," Clinical Science, vol. 80, no. 4, pp. 309-312, 1991.

[37] K. R. Kendrick, S. C. Baxi, and R. M. Smith, "Usefulness of the modified 0-10 Borg scale in assessing the degree of dyspnea in patients with COPD and asthma," Journal of Emergency Nursing, vol. 26, no. 3, pp. 216-222, 2000.

[38] G. Borg, "Perceived exertion as an indicator of somatic stress," Scandinavian Journal of Rehabilitation Medicine, vol. 2, no. 2, pp. 92-98, 1970.

[39] R. L. Kolotkin and R. D. Crosby, "Psychometric evaluation of the impact of weight on quality of life-lite questionnaire (IWQOL-Lite) in a community sample," Quality of Life Research, vol. 11, no. 2, pp. 157-171, 2002.

[40] R. L. Kolotkin, R. D. Crosby, K. D. Kosloski, and G. R. Williams, "Development of a brief measure to assess quality of life in obesity," Obesity Research, vol. 9, no. 2, pp. 102-111, 2001.

[41] S. G. Engel, R. D. Crosby, R. L. Kolotkin, et al., "Impact of weight loss and regain on quality of life: mirror image or differential effect?" Obesity Research, vol. 11, no. 10, pp. 12071213, 2003.

[42] R. L. Kolotkin, R. D. Crosby, G. R. Williams, G. G. Hartley, and S. Nicol, "The relationship between health-related quality of life and weight loss," Obesity Research, vol. 9, no. 9, pp. 564$571,2001$.

[43] M. A. White, P. M. O’Neil, R. L. Kolotkin, and T. K. Byrne, "Gender, race, and obesity-related quality of life at extreme levels of obesity," Obesity Research, vol. 12, no. 6, pp. 949-955, 2004.

[44] J. K. Larsen, R. Geenen, B. van Ramshorst, et al., "Binge eating and exercise behavior after surgery for severe obesity: a structural equation model," International Journal of Eating Disorders, vol. 39, no. 5, pp. 369-375, 2006.

[45] J. Roelofs, L. Goubert, M. L. Peters, J. W. S. Vlaeyen, and G. Crombez, "The Tampa Scale for Kinesiophobia: further examination of psychometric properties in patients with chronic low back pain and fibromyalgia," European Journal of Pain, vol. 8, no. 5, pp. 495-502, 2004.

[46] A. Bandura, Self-Efficacy: The Exercise of Control, W.H. Freeman, New York, NY, USA, 1997.

[47] CVZ, Farmacotherapeutisch Kompas, Bohn Stafleu van Loghum, Houten, The Netherlands, 2007.

[48] S. Schelling, S. Munsch, A. H. Meyer, P. Newark, E. Biedert, and J. Margraf, "Increasing the motivation for physical activity in obese patients," International Journal of Eating Disorders, vol. 42, no. 2, pp. 130-138, 2009.

[49] T. S. Church, C. P. Earnest, J. S. Skinner, and S. N. Blair, "Effects of different doses of physical activity oncardiorespiratory fitness among sedentary, overweight or obese 
postmenopausal women with elevated blood pressure: a randomized controlled trial," Journal of the American Medical Association, vol. 297, no. 19, pp. 2081-2091, 2007.

[50] A. Quinn, C. Doody, and D. O'Shea, "The effect of a physical activity education programme on physical activity, fitness, quality of life and attitudes to exercise in obese females," Journal of Science and Medicine in Sport, vol. 11, no. 5, pp. 469$472,2008$.

[51] "Clinical guidelines on the identification, evaluation, and treatment of overweight and obesity in adults - the evidence report. National Institutes of Health," Obesity Research, vol. 6, supplement 2, pp. 51S-209S, 1998.

[52] I. Janssen, P. T. Katzmarzyk, R. Ross, et al., "Fitness alters the associations of BMI and waist circumference with total and abdominal fat," Obesity Research, vol. 12, no. 3, pp. 525-537, 2004.

[53] W. C. Levy, M. D. Cerqueira, G. D. Harp, et al., "Effect of endurance exercise training on heart rate variability at rest in healthy young and older men," American Journal of Cardiology, vol. 82, no. 10, pp. 1236-1241, 1998.

[54] E. J. C. De Geus, L. J. P. van Doornen, D. C. de Visser, and J. F. Orlebeke, "Existing and training induced differences in aerobic fitness: their relationship to physiological response patterns during different types of stress," Psychophysiology, vol. 27, no. 4, pp. 457-478, 1990.

[55] P. T. Katzmarzyk, I. Janssen, R. Ross, T. S. Church, and S. N. Blair, "The importance of waist circumference in the definition of metabolic syndrome: prospective analyses of mortality in men," Diabetes Care, vol. 29, no. 2, pp. 404-409, 2006.

[56] S. Klein, D. B. Allison, S. B. Heymsfield, et al., "Waist circumference and cardiometabolic risk: a consensus statement from Shaping America's Health: association for Weight Management and Obesity Prevention; NAASO, the Obesity Society; the American Society for Nutrition; and the American Diabetes Association,” Diabetes Care, vol. 30, no. 6, pp. 16471652, 2007.

[57] W. J. Gibbons, N. Fruchter, S. Sloan, and R. D. Levy, "Reference values for a multiple repetition 6-minute walk test in healthy adults older than 20 years," Journal of Cardiopulmonary Rehabilitation, vol. 21, no. 2, pp. 87-93, 2001.

[58] F. B. Wyatt, S. Milam, R. C. Manske, and R. Deere, "The effects of aquatic and traditional exercise programs on persons with knee osteoarthritis," Journal of Strength and Conditioning Research, vol. 15, no. 3, pp. 337-340, 2001.

[59] T.-J. Wang, B. Belza, F. Elaine Thompson, J. D. Whitney, and K. Bennett, "Effects of aquatic exercise on flexibility, strength and aerobic fitness in adults with osteoarthritis of the hip or knee," Journal of Advanced Nursing, vol. 57, no. 2, pp. 141-152, 2007.

[60] M. R. Assis, L. E. Silva, A. M. Alves, et al., "A randomized controlled trial of deep water running: clinical effectiveness of aquatic exercise to treat fibromyalgia," Arthritis Rheumatism, vol. 55, no. 1, pp. 57-65, 2006.

[61] T. A. Wadden and A. J. Stunkard, Handbook of Obesity Treatment, The Guilford Press, New York, NY, USA, 2004. 


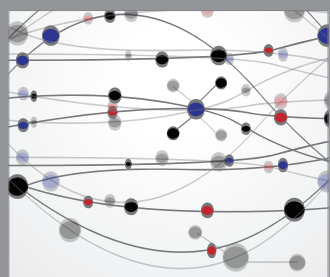

The Scientific World Journal
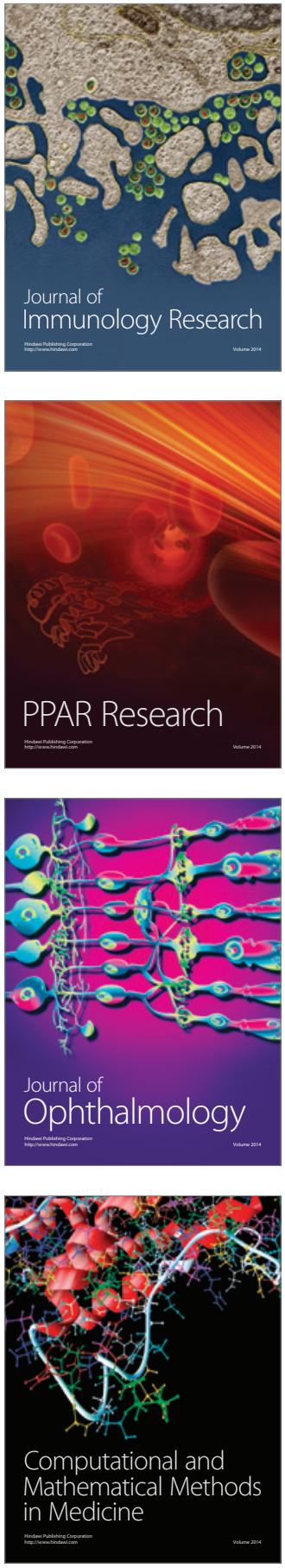

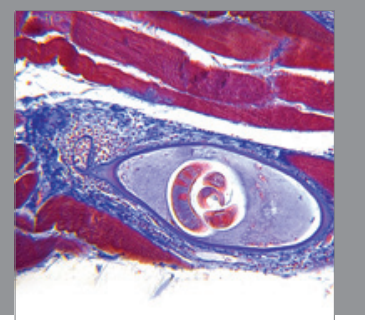

Gastroenterology

Research and Practice
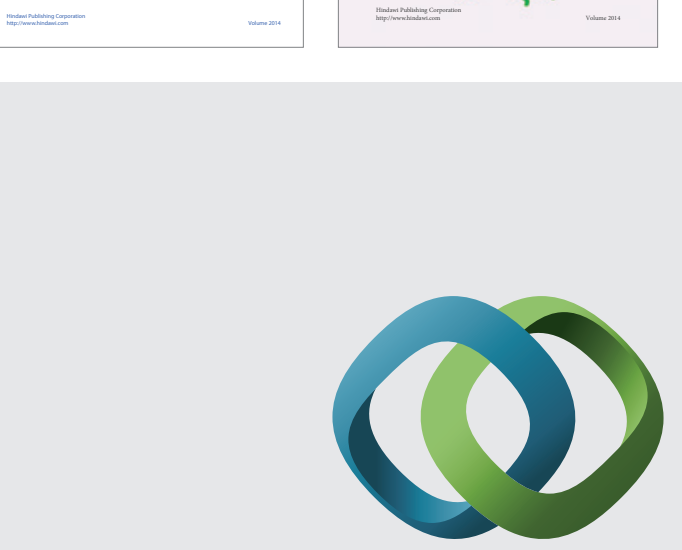

\section{Hindawi}

Submit your manuscripts at

http://www.hindawi.com
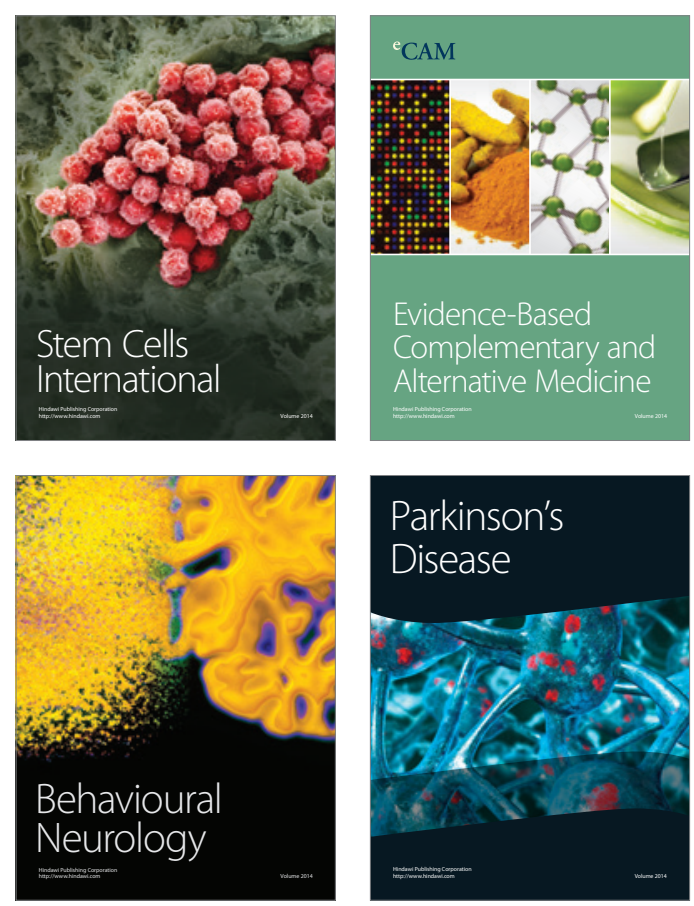

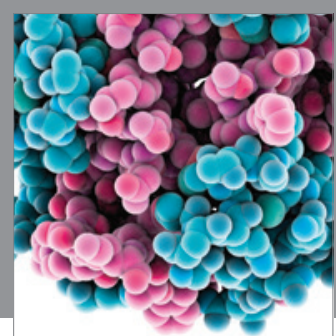

Journal of
Diabetes Research

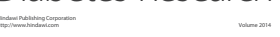

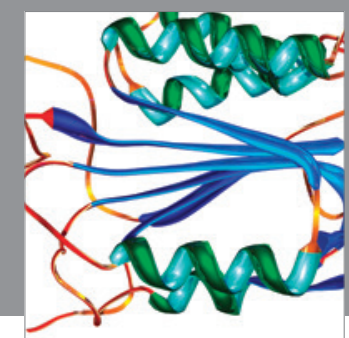

Disease Markers
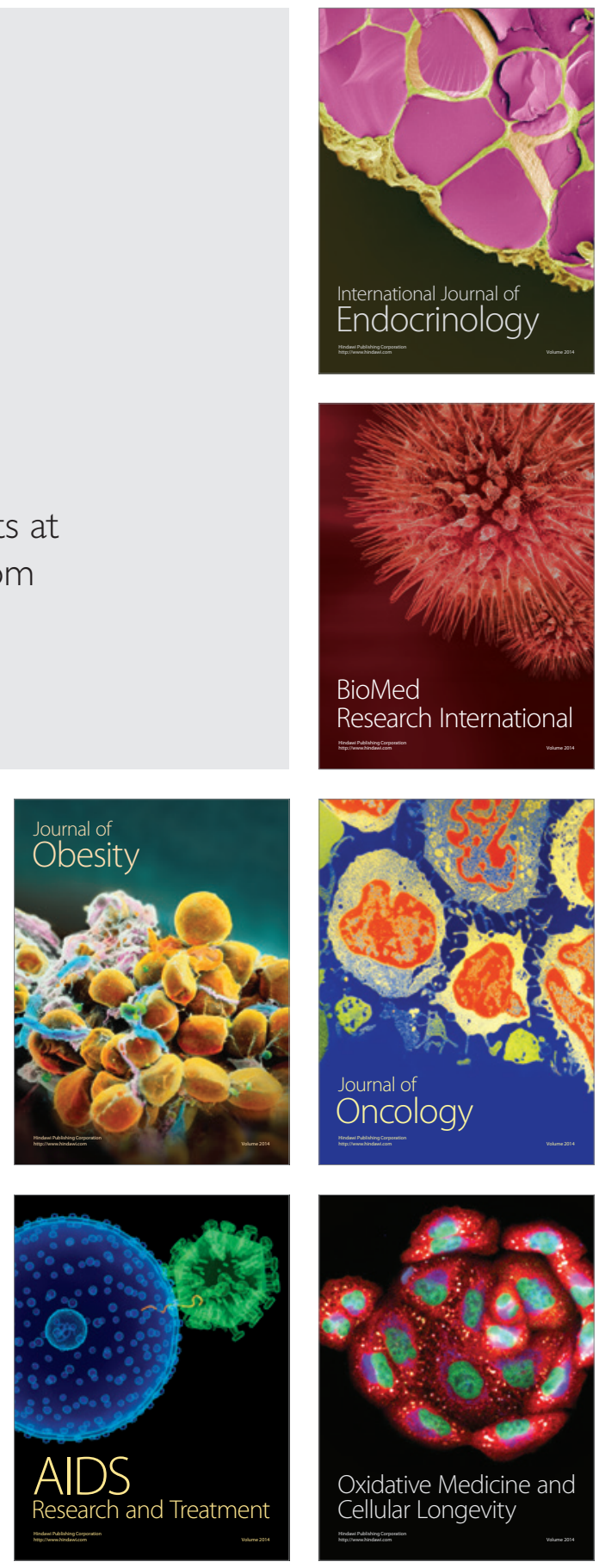